\title{
Fluktuasi asimetri ikan nila (Oreochromis niloticus) di Pusat Pelatihan Mandiri Kelautan dan Perikanan (P2MKP) Dunia Air, Banyuwangi
}

\section{Fluctuations of tilapia asymmetry (Oreochromis niloticus) at Marine Mandiri Fisheries Training Center (P2MKP) Water World, Banyuwangi}

\author{
Darmawan Setia Budi $i^{*}$, Lailatul Lutfiyah ${ }^{1}$ \\ ${ }^{1}$ Program Studi Budidaya Perairan PSDKU Banyuwangi, Universitas Airlangga \\ Jl. Wijaya Kusuma No. 113, Banyuwangi 68425, Indonesia \\ *darmawansetiabudi@fpk.unair.ac.id
}

\begin{abstract}
Abstrak
Fluktuasi asimetri karakter meristik bilateral merupakan salah satu metode sederhana yang dapat digunakan untuk mengetahui stabilitas perkembangan ikan. Penelitian ini bertujuan untuk mengetahui informasi kuantitatif mengenai level asimetri ikan nila (Oreochromis niloticus) di Pusat Pelatihan Mandiri Kelautan dan Perikanan (P2MKP) Dunia Air, Banyuwangi. Sebanyak 120 ekor ikan nila $(5-7 \mathrm{~cm})$ diamati dalam penelitian ini. Karakter meristik bilateral yang dihitung adalah jumlah jari-jari lemah sirip dada, jumlah jari-jari lemah sirip perut, jumlah sisik pada linea lateralis atas, sisik pada line lateralis bawah. Hasil penelitian menunjukkan bahwa nilai fluktuasi asimetri besaran (FAm) dan nilai fluktuasi asimetri bilangan (FAn) terbesar terdapat pada sisik pada linea lateralis atas yaitu sebesar 2.14 dan 0.78. Sedangkan nilai FAm dan FAn terkecil terdapat pada jarijari lemah sirip ventral yaitu sebesar 1.69 dan 0.73 . Nilai total FAm dan FAn dari semua organ yang diamati adalah 7.83 dan 2.99 .
\end{abstract}

Kata Kunci : fluktuasi asimetri, ikan nila, P2MKP Dunia Air

\section{Abstract}

Fluctuating asymmetry of the bilateral meristic characteristic is one of the simple methods that can be used to determine the stability of an individual fish development. This study aims to provide quantitative information about the level of asymmetry of Nile tilapia (Oreochromis niloticus) in Dunia Air Independent Training Center Marine and Fisheries, Banyuwangi through bilateral meristic characteristic observation. A total of 120 fish samples $(5-7 \mathrm{~cm})$ were measured in this study. Four bilateral meristic characters were calculated i.e. the number of soft pectoral fins, number of soft ventral fins, number of scales on the lateral line up and down. The results show that the highest value of the fluctuating asymmetry of magnitude (FAm) and fluctuating asymmetry of number (FAn) was obtained at the number of scales on the lateral line up those are 2.14 and 0.78 , respectively. Meanwhile, the lowest FAm and FAn values obtained from the soft ventral fins which were 1.69 and 0.78 , respectively. The sum of the total value of fluctuating asymmetry of each bilateral meristic characteristic was observed. The overall FAm value was 7.83 and the overall FAn value was 2.99.

Keywords: fluctuating asymmetry, Nile tilapia, PMKP Dunia Air

PENDAHULUAN

Ikan nila (Oreochromis

niloticus) merupakan salah satu

komoditas utama ikan konsumsi di dunia. Benih yang berkualitas sangat diperlukan untuk menunjang keberhasilan dan kontinuitas produksi budidaya ikan nila. Pusat Pelatihan 
Mandiri Kelautan dan Perikanan (P2MKP) Dunia Air merupakan salah satu produsen benih ikan nila di Kabupaten Banyuwangi yang menyediakan benih untuk didistribusikan pada pembudidaya.

Penurunan kualitas benih ikan nila mulai dirasakan oleh petani ikan. Hal tersebut ditandai dengan banyaknya ikan abnormal yang menyebabkan rendahnya pertumbuhan dan kelangsungan hidup. Abnormalitas ikan yang sering dijumpai adalah adanya benih ikan yang pertumbuhannya sangat lambat dan tidak proporsional (kerdil), kecenderungan lebih melengkungnya kepala ikan hasil budidaya dibandingkan dengan ikan di alam bebas, ketidakadaan operkulum (tutup insang) sehingga insang ikan mudah terserang penyakit, bagian sirip dorsal yang membengkok ke dalam tubuh, serta scoliosis (Budi, 2017).

Kualitas benih ikan nila ditentukan oleh banyak faktor. Secara genetik berbagai fenomena abnormalitas benih dapat terjadi karena tingginya tekanan silang dalam (inbreeding) yang bisa diakibatkan karena sedikitnya jumlah induk dan perkawinan sekerabat, sehingga menyebabkan rendahnya variasi genetik (Sheridan \& Pomiankowski, 1997). Depresi inbreeding lebih sering teramati pada riwayat perkawinan ikan dibandingkan dengan morfologinya (DeRose \& Roff, 1999). Beberapa studi menunjukkan bahwa depresi inbreeding dapat dibuktikan pada stabilitas perkembangan morfologi (Alibert et al., 1994).

Rendahnya kualitas genetik dapat berakibat negatif terhadap sifat penting dalam budidaya ikan, antara lain menurunnya kelangsungan hidup dan pertumbuhan. Secara genetik, fenomena ini terjadi karena menurunnya stabilitas perkembangan individu yang juga dicirikan dengan meningkatnya individu yang asimetri dan abnormal (Vøllestad et al., 1999).

Menurut Clarke (1992), kestabilan perkembangan organ berpasangan pada hewan berhubungan erat dengan tingkat keragaman genetiknya. Kestabilan organ-organ berpasangan disebut dengan fluktuasi asimetri. Nilai stabilitas perkembangan organ berpasangan diukur dengan dua angka, yaitu dengan bilangan 
(number) rataan sifat asimetri per individu dan dengan angka rataan besaran (magnitude) sifat asimetri. Pengukuran stabilitas perkembangan dengan kedua angka tersebut pada setiap individu yang kemudian diperoleh nilai tengah dari keseluruhan asimetri dapat digunakan untuk menduga berkurangnya keragaman genetik akibat silang dalam suatu populasi ikan ( $\underline{\text { Alibert } e t}$ al., 1994). Walaupun relatif sederhana fluktuasi asimetri dapat menunjukkan adanya perbedaan kestabilan perkembangan. Adanya perbedaan fenotip pada individu untuk sifat meristik bilateral dapat menunjukkan fluktuasi asimetri, yaitu adanya perbedaan antara karakter sisi kiri dan sisi kanan tubuh yang menyebar secara normal dengan rataan mendekati nol sebagai akibat ketidakmampuan inividu untuk bisa berkembang secara tepat dan normal (Clarke, 1995).

Beberapa penelitian mengenai fluktuasi asimetri pada ikan nila telah dilakukan untuk mengetahui kualitas genetiknya sebagai dasar informasi untuk program pemuliaan ikan nila (Fessehaye et al., 2007; Widiyati \& Sumantadinata, 2007; Budi, 2107).
Tujuan penelitian ini adalah untuk mengetahui informasi kuantitatif mengenai tingkat asimetri pada ikan nila (Oreochromis niloticus) sebagai referensi program breeding di P2MKP Dunia Air.

\section{METODOLOGI PENELITIAN}

\section{Waktu dan Tempat}

Penelitian ini dilaksanakan pada bulan Agustus 2017, bertempat di laboratorium Anatomi Universitas Airlangga PSDKU Banyuwangi dan P2MKP Dunia Air.

\section{Sampel Ikan dan Pengukuran Meristik}

Ikan yang digunakan pada penelitian ini berukuran 5-7 cm sebanyak 120 ekor. Ikan nila yang dijadikan sebagai ikan sampel dipilih yang bagus (tidak rusak karena penanganan), kemudian diambil secara acak. Pengamatan stabilitas perkembangan individu ikan melalui pendekatan presentase asimetri dan fluktuasi asimetri, yaitu dengan cara membandingkan jumlah beberapa karakter meristik bilateral pada sisi kanan dan sisi kiri setiap individu ikan uji.

Karakteristik

meristik bilateral yang diamati adalah jumlah 
jari-jari lemah sirip dada, jumlah jarijari lemah sirip perut, jumlah sisik pada linea lateralis atas, dan jumlah sisik pada linea lateralis bawah. Cara penghitungan karakter meristik bilateral tersebut berpedoman pada Saanin (1984). Data hasil perhitungan semua karakter yang diamati, dihitung nilai fluktuasi asimetrinya, baik fluktuasi asimetri besaran (magnitude) maupun bilangan (number). Fluktuasi asimetri besaran (magnitude) adalah nilai yang didapat dari jumlah selisih karakter yang diamati pada sebelah kanan dan kiri dibagi dengan total jumlah sampel yang diamati. Sedangkan fluktuasi asimetri bilangan (number) adalah jumlah individu yang asimetris yang ditemukan dalam pengamatan dibagi dengan banyaknya sampel yang diamati. Rumus yang digunakan dalam penghitungan fluktuasi asimetri adalah sebagai berikut (Leary et al., 1985a):

$$
F A m=\frac{\sum(L-R)}{n},
$$

$F A n=\frac{\sum(Z)}{n}$

Keterangan :

L : Jumlah organ sisi kiri

R : Jumlah organ sisi kanan
$\mathrm{Z}$ : Jumlah individu asimetri untuk ciri meristik tertentu

Fam : Fluktuasi asimetri besaran

FAn : Fluktuasi asimetri bilangan

n : Jumlah sampel

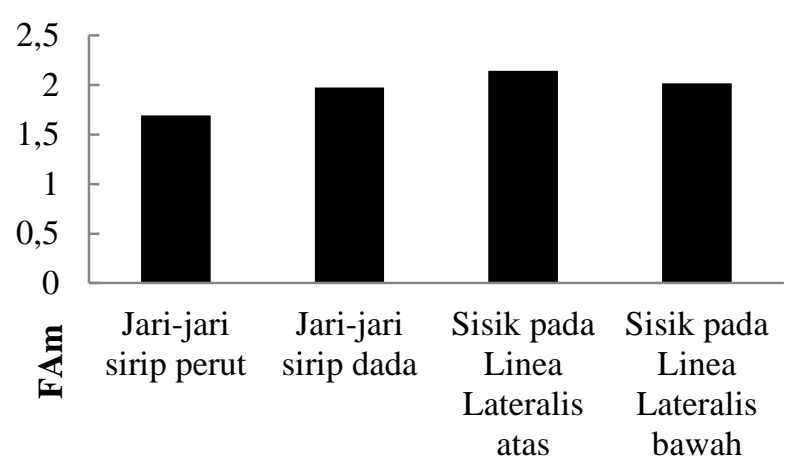

Berdasarkan masing-masing karakter yang diamati dapat dicari nilai fluktuasi asimetri gabungan (overall). Fluktuasi asimetri gabungan bisa didapatkan dari hasil penjumlahan dari nilai fluktuasi asimetri total masing-masing karakter meristik bilateral yang diamati. Data hasil percobaan dianalisis secara deskriptif dan ditampilkan dalam bentuk grafik.

\section{HASIL DAN PEMBAHASAN}

Hasil pengukuran nilai fluktuasi asimetri bilangan (FAm) maupun besaran (FAn) dapat dilihat pada gambar 1 dan 2. Berdasarkan kedua gambar tersebut diketahui bahwa nilai terbesar dari FAm dan FAn terdapat pada jumlah sisik pada linea lateralis atas yaitu FAm sebesar 
2.14 (dari 100 ekor ikan sampel yang diperiksa, jumlah selisih antara karakter meristik sebelah kanan dan kiri sebesar 214 buah) dan FAn sebesar 0.78 (dari 100 ekor ikan sampel yang diperiksa, terdapat 78 ekor individu yang asimetris). Nilai FAm dan FAn pada jumlah sisik pada linea lateralis bawah sebesar 2.02 dan 0.75 . Selanjutnya pada jari-jari lemah sirip dada didapat nilai FAm sebesar 1.98 dan nilai FAn sebesar 0,74. Sedangkan, nilai FAm dan FAn terkecil diperoleh pada jari-jari lemah sirip perut yaitu sebesar 1.69 dan 0.73. Sementara itu, nilai FAm gabungan sebesar 7.83 dan nilai FAn gabungan sebesar 2.99 (Gambar 3.).

Gambar 1. Fluktuasi asimetri besaran (FAm) ikan nila di Pusat Pelatihan Mandiri Kelautan dan Perikanan (P2MKP) Dunia Air, Banyuwangi.

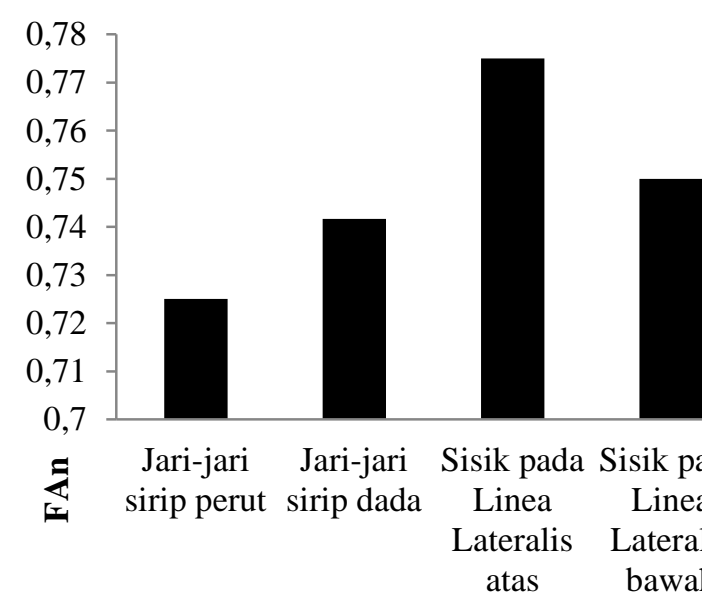

Gambar 2. Fluktuasi asimetri bilangan (FAn) ikan nila di Pusat Pelatihan Mandiri Kelautan dan Perikanan (P2MKP) Dunia Air, Banyuwangi.

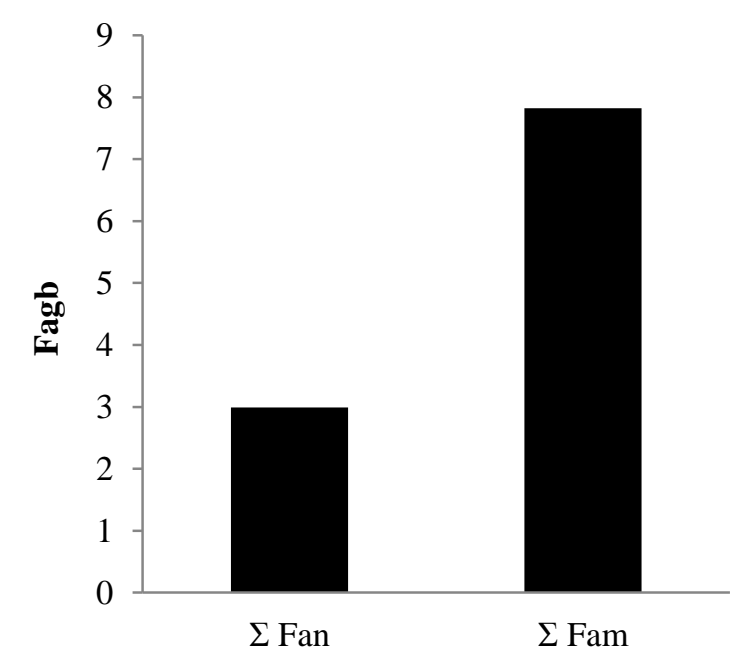

Gambar 3. Fluktuasi asimetri gabungan (FAgb) ikan nila di Pusat Pelatihan Mandiri Kelautan dan Perikanan (P2MKP) Dunia Air, Banyuwangi.

Tingginya nilai fluktuasi asimetri karakteristik meristik bilateral suatu organ dikarenakan organ tersebut mendapat prioritas energi yang lebih kecil untuk perkembangannya dibandingkan dengan karakter meristik bilateral lainnya (Handoyo, 2002). Berdasarkan hasil penelitian diketahui bahwa nilai fluktuasi asimetri besaran (FAm) dan fluktuasi asimetri bilangan (FAn) terbesar ada pada jumlah sisik pada linea lateralis. Nilai fluktuasi asimetri dari jumlah sisik pada linea lateralis yang tinggi 
disebabkan karena jumlah sisik pada organ tersebut (number) lebih banyak jika dibandingkan dengan jari-jari lemah sirip dada dan sirip perut sehingga energi yang digunakan untuk perkembangan sisik pada linea lateralis tidak tercukupi.

Sementara itu, nilai FAm dan FAn pada jari-jari lemah sirip dada lebih besar dari jari-jari lemah sirip perut. Hasil yang sama juga diperoleh pada pengamatan fluktuasi asimetri ikan mas dengan nilai FAm dan FAn jari-jari lemah sirip dada sebesar 0,80 dan 0,74 dibandingkan jari-jari lemah sirip perut sebesar 0,40 dan 0,40 (Sugiarto, 1991).

FAm gabungan dan FAn gabungan (overall) yang diperoleh menunjukkan nilai yang cukup tinggi jika dibandingkan dengan hasil penelitian Widiyati \& Sumantadinata (2007), dimana nilai FAm gabungan dan FAn gabungan pada ikan nila yang berasal dari Sukamandi sebesar 2,84 dan 1,75 serta FAm gabungan dan FAn gabungan pada ikan nila yang berasal dari Danau Tempe sebesar 1,40 dan 0,80. Tingginya nilai fluktuasi asimetri yang didapat disebabkan oleh rendahnya keragaman genetik yang berhubungan dengan terjadinya silang dalam (inbreeding) yang dapat meningkatkan homozigositas. Jumlah induk yang sedikit memungkinkan terjadinya perkawinan antara individu sekerabat yang dapat menyebabkan terjadinya anakan yang homozigot (Hardjamulia, 1999). Inbreeding diduga memberikan efek pada stabilitas perkembangan morfologi karena kurangnya keragaman enzimatik pada individu homozigot dapat megurangi efisiensi perkembangan normal proses homeostasis. (Fessehaye et al., 2007) Leary et al. (1985a) menyatakan bahwa terdapat hubungan positif antara homozigositas dengan rendahnya stabilitas perkembangan individu yang diukur dengan fluktuasi asimetri. Menurut Leary et al. (1985b), individu yang heterozigositasnya tinggi akan memiliki kestabilan perkembangan yang tinggi dan memiliki ciri fenotip mendekati ciri fenotip yang dimiliki oleh populasi normal atau sering disebut homeostatis tinggi. 


\section{KESIMPULAN}

Nilai tertinggi fluktuasi asimetri besaran (FAm) dan fluktuasi asimetri bilangan (FAn) ikan nila di Pusat Pelatihan Mandiri Kelautan dan Perikanan (P2MKP) Dunia Air Banyuwangi terdapat pada jumlah sisik pada linea lateralis atas, selanjutnya diikuti jumlah sisik pada linea lateralis bawah, jumlah jari-jari lemah sirip dada, dan jumlah jari-jari lemah sirip perut.

\section{DAFTAR PUSTAKA}

Alibert, P., Renaud, S., Dod, B., Bonhomme, F., Auffray, J.C. 1994. Fluctuating asymmetry in the Mus musculus hybrid zone: heterotic effect in disrupted coadapted genomes. Proceedings of the Royal Society $B$ : Biological Sciences 258, 5359.

Budi, D.S., Lutfiyah, L. and Triastuti, R.J., 2017. Fluctuating Asymmetry of Red Tilapia (Oreochromis niloticus) in Genteng Fish Hatchery Center, Banyuwangi. OmniAkuatika, 13(1).

Clarke, G.M. 1992. Fluctuating asymmetry: A technique for measuring developmental stress off genetic and environmental origin. Acta Zoology Fennica 191, 31-35.

Clarke, G. M. 1995. Relationships between developmental stability and fitness: application for conservation biology. Conservation Biology 9, 18-24.

DeRose, M.A., Roff D.A. 1999. A comparison of inbreeding depression in life-history and morphological traits in animals. Evolution 53, 1288-1292.

Fessehaye, Y., Komen, H., Rezk, M.A., van Arendonk, J.A., Bovenhuis, H. 2007. Effects of inbreeding on survival, body weight and fluctuating asymmetry (FA) in Nile tilapia, Oreochromis niloticus. Aquaculture 264(1), 27-35.

Handoyo B. 2002. Fluktuasi asimetri pada ikan kerapu tikus (Cromileptes altiveis) di Balai Budidaya Air Payau (BBAP) Situbondo, Jawa Timur. [Skripsi]. Bogor: Institut Pertanian Bogor.

Hardjamulia A. 1999. Pengelolaan dan penyebaran induk pejenis ikan air tawar mendukung pelepasan varietas. Prosiding Pertemuan Perekayasaan Teknologi Perbenihan Agrobisnis Ikan Air Tawar, Payau, dan Laut. Direktorat Jendral Perikanan, Departemen Pertanian. Jakarta. Hal 8-5.

Leary, R.F., Allendorf, W., Knudsen. 1985a. Development instability as an indicator of reduced genetic variation in hatchery trout. Transaction of the American Fisheries Society 144, 230-235.

Leary, R.F., Allendorf, W., Knudsen. 1985b. Development instability 
as high meristic count indicator of reduced genetic variation in hatchery trout. Transaction of the American Fisheries Society 144, 230-235.

Popma, T., Masser, M. 1999. Tilapia: Life history and biology. SRAC Publication No. 283. Southern Regional Aquaculture Center, Stoneville, MS.

Saanin H. 1984. Taksonomi dan kunci identifikasi Ikan I dan II. Bina Cipta. Bandung.

Sheridan, L., Pomiankowski, A. 1997. Fluctuating asymmetry, spot asymmetry and inbreeding depression in the sexual coloration of male guppy fish. Heredity 79(5), 515-523.

Sugiarto. 1991. Quantitative characters of first generation of diploid mitotic ginogenetic and diploid meiotik and ginogenetic of Majalaya common carp (Cyprinus carpio L) Majalaya. [Thesis]. Bogor: Institut Pertanian Bogor.

Vøllestad, L.A., Hindar, K., Møller, A.P. 1999. A meta-analysis of fluctuating asymmetry in relation to heterozygosity. Heredity 83(2), 206-218.

Widiyati, A., Sumantadinata, K. 2007. Fluctuating asymmetry of 69 tilapia (Oreochromis niloticus) from Lake Tempe (South Sulawesi) and GIFT tilapia of Sukamandi, Jatiluhur, and Sukabumi. Jurnal Riset Akuakultur 2(3), 395-398. 
